\title{
И.М. Куликова
}

\section{СЕМАНТИЧЕСКОЕ НАПОЛНЕНИЕ МИФОЛОГЕМЫ ДЕРЕВА В НАТУРФИЛОСОФИИ П.С. БАХЛЫКОВА}

В статье рассмотрены семантические варианты мифологемы «дерево» в романе югорского писателя П. Бахлыкова «Медвежья падь», где она выступает одной из доминант формальной и содержательной организации художественного пространства. В натурфилософии автора данная мифологема играет важную роль: она позволяет описать основные параметры бытия и реконструировать универсальную мифопоэтическую концепцию мироустройства. Семантическая структура образа дерева в романе восходит к архетипическим основам мировоззрения русского и хантыйского народов, населяющих Сибирь. В статье анализируются значение и функции реальных природных объектов - таких пород деревьев, как кедр, береза, ель, лиственница, сосна - в мифологии, в формировании сакрального пространства, в культовой практике. Эти деревья являются маркерами священных центров, могут служить символами Мирового дерева и Дерева жизни. Основная роль в романе отведена образу кедра, культ которого получил наибольшее развитие на территории, ставшей объектом описания в произведении.

Ключевые слова: П.С. Бахлыков, роман «Медвежья падь», мифологема, Мировое древо, Древо жизни, угорская мифология, славянская мифология.

DOI: $10.35634 / 2412-9534-2021-31-3-608-613$

П.С. Бахлыков принадлежал к писателям, стремившимся философски осмыслить место и роль человека в мире. Его «концепция сущего» во многом совпадала с натурфилософией представителей русской «деревенской прозы»- В. Астафьева, С. Залыгина, В. Распутина и др. Его творчество пересекалось с мотивами произведений крупных этнических писателей (Е. Айпина, Ю. Шесталова, А. Неркаги, Ю. Рытхэу и др.), что обусловлено его интересом к культуре, мировоззрению, этнографии юганских ханты. Писателей сближали общая проблематика, ориентированная на традиционные, природные начала бытия, вырабатываемая поэтика, система персонажей.

Перу П. Бахлыкова принадлежит только один художественный текст - роман «Медвежья падь», который так и остался по существу не исследованным. Две статьи [2, с. 5-16; 11, с. 7-28] и критические отзывы $[11$, с. 133] не дают полной картины его проблемно-тематического и художественного своеобразия. Вместе с тем актуальность романа определяется как внешними причинами (отношения человека и природы в условиях современной цивилизации), так и собственно научными исканиями: возникновением филологической регионалистики, основной задачей которой является «изучение широкого спектра местнографических реалий» $[12$, с. 10], позволяющих посмотреть на творчество региональных писателей с новой точки зрения. В таких текстах локальная картина мира и культурный ландшафт ярче всего выявляются в границах изучения поэтики пространства, или геопоэтики (К. Уайт), которая может быть определена как «ментальное, интеллектуальное, художественное освоение человеком географического пространства» [4, с. 337], отражая глубинную связь созданного образа «с мироощущением человека, его психологическими, мировоззренческими, поведенческими реакциями» $[1$, c. 5]. Художественная структура таких тестов во многом основывается на совмещении символики архетипов и мифологем с реалиями конкретного этнографического ландшафта, что позволяет «разомкнуть» границы локального пространства и придать ему общечеловеческий ценностный статус. В моделируемом П. Бахлыковым в «Медвежьей пади» локусе важную роль играет мифологема дерева, имеющая свою семантику и свое аксиологическое поле. Однако этот аспект художественного пространства романа остался вне поля зрения исследователей.

Будучи непрофессиональным писателем, П. Бахлыков зачастую ориентировался на «чужой» опыт, прежде всего писателей-«деревенщиков», которые в поиске онтологических оснований сущего нередко обращались к символике мифов (чаще языческих, чем библейских) либо к архаическим воззрениям как наиболее универсальным. Сближает П. Бахлыкова с писателями-сибиряками и использование приема совмещения концептов, разных по своим культурным основаниям. В «Медвежьей пади» - это «наложение» славянских и угорских конструктов, что связано с особенностями заселения территории Югры, уникальный образ которой создал писатель. Безусловно, П. Бахлыков не столь ак- 
тивно (как, например, В. Распутин) пользовался приемом «включения» мифопоэтической парадигмы в метафизические рамки конкретной территории. Но в художественном пространстве его романа выделяется символика общемировых универсалий, архетипов, этнических мифологем, прослеживаются определенные ассоциации с древними представлениями.

Так, в стилистике романа П. Бахлыкова можно отметить реминисценции с мифологемой Мирового дерева, выступающего одной из доминант формальной и содержательной организации пространства. При этом автор отталкивается от мифопоэтических концепций мироустройства двух народов - русских и ханты. Согласно славянским представлениям, Мировое древо находится на острове Буяне в центре водного пространства $[14$, с. $31,68,260]$. В «деревенской прозе» символика образа наиболее полно была обыграна В. Распутиным в «Прощании с Матёрой»: это своеобразная ось, скрепляющая мир; место «акта творения» (вода), «середина мира»; место пересечения макрокосма и микрокосма [8, с. 333-336]. В тексте сообщается, что, согласно поверью, «царским Лиственем» «крепится остров к речному дну, к одной общей земле» [13, с. 153], фиксируя устойчивость бытия и утверждая единство мироздания. Когда Матёра будет «похоронена» под водой, Павел станет искать ее в центре водного пространства [13, с.186]. Отголоски этого мифа у П. Бахлыкова можно отметить в мотиве нахождения такого дерева (отождествляемого с Мировым) на острове, в окружении воды как стихии первотворения. В трактовке образа писатель ближе к мифопоэтическим представлениям угров о Мировом дереве, крона которого касается неба, а корни уходят глубоко в землю, символизируя «соединение миров» [5, с. 85]. Реминисценции с угорским вариантом мифа можно отметить в предпоследней главе романа. Здесь дано описание поляны с громадными кедрами и елями - столь высокими, что «их вершины пронзали небо, а проплывающие облака касались их ветвей» [2, с. 228]. Под одной из таких елей стоит «древний идол...с печальными глазами», словно «освящая» это место, подчеркивая его сакральность как «центра мира», поскольку Мировое древо может дифференцироваться (предстать как два-три и более деревьев) [8, с. 330]. Подчеркивает сакральность места и актуализация факта того, что раньше здесь было остяцкое святилище. Это отражает особенности архаического мышления, ориентированного на выделение центров, определяющих координаты конкретного пространственно-временного единства и обеспечивающих соблюдение природного и социального порядка $[8$, с. 678]. Упоминание о неизвестно как и почему возникшей рядом, в низменном месте, гоpe, наверху которой «росли вековые деревья» и вокруг которой поставили свое городище первые поселившиеся здесь остяки, отсылает к той же мифологеме: гора в космологии угро-самодийских народов может выступать в качестве варианта Мирового дерева [8, с. 257]. И хотя образ горы здесь подвергся существенной демифологизации и десакрализации, он все же не стал «простым локальным указателем» (В. Топоров). Этот образ можно трактовать как обозначение того, что было «в начале», связав с одним из сюжетов о сотворении мира, согласно которому гора (в мировоззренческой системе уральских народов - Уральские горы) выступает в качестве космической опоры [8, с. 886].

К категории почитаемых и священных относились и отдельные деревья, особенно старые, располагавшиеся изолированно и напрямую не связанные с миром людей. Выделение в пространстве романа «могучего, в три обхвата, кедра» более других вызывает ассоциации с архетипом Мирового древа. В соответствии с мифопоэтической символикой «могучий кедр» расположен в глубине тайги, выделяясь на фоне остальных деревьев («самое видное дерево», по выражению К. Карьялайнена). Стоящая рядом с кедром ель, соотносимая в мифологии угров с представлениями о нижнем мире, может выполнять функции Мирового древа [9, с. 388, 409]. Образ «соседки-ели», которой не дал погибнуть подхвативший ее в свои объятия могучий кедр, подчеркивает «центральное» положение этого дерева в пространстве окружающего природного мира. Образ кедра в целом вызывает реминисценции с угро-самодийским мифом о первом дереве, выросшем на клочке земли посреди воды в эпоху первотворения. Косвенно «заглавную» роль этого дерева подтверждает и фамилия главного героя - Прокопия Кедрова. «Отношения» кедра и ели сопоставимы с историей «дружбы» Лиственя и березы у В. Распутина («Быть может, корни их под землей сходились, знали согласие» [13, с. 155]). Кедр и Листвень все еще сохраняют свою могучую силу, несмотря на древний возраст, ель и береза, существующие благодаря «поддержке» этих крепких деревьев, уже истратили жизненную энергию («состарились», «устали»). В этой ипостаси образ кедра сопоставим с некоторыми содержательными аспектами мифологемы Дерева жизни (как варианта Мирового древа), воплощающего всю полноту сущего. По утверждению М. Косарева, в шаманизме и в сибирском язычестве в целом две функции вселенского дерева («мировая ось» и «древо жизни») органически переплетены и взаимосвязаны 
[7, с. 248-249]. По наблюдениям И. Бедаревой, сходные тенденции в использовании художественного потенциала образа кедра как ключевого символа алтайской мифологии проявляются в русской литературе Горного Алтая [3].

Вместе с тем в роли Небесного либо Мирового дерева у народов Сибири и Урала чаще выступает береза $[7$, с. 240; 5, с. 85-86]. Д. Зеленин выделял ее как одно из наиболее важных культовых деревьев у славян и некоторых сибирских этносов $[6$, с. 64,71$]$. А. Гейштор отмечает, что березу особенно ценили угро-финские народы и жители северо-восточной Руси [16, s. 200-202]. Береза, наряду с елью и сосной, выполняла роль космического, мирового дерева в удмуртской мифологии [15, с. 64]. Культ березы как Мирового дерева с семью ветвями и семью корнями широко распространен у ненцев [8, с. 887]. Но в романе П. Бахлыкова береза остается в основном приметой реального ландшафта, описание ее дается в соответствии с русской поэтической традицией («Березы низко склонили свои дивные косы»; «березовые рощи, распустив свои длинные косы с молодой клейкой листвой»; «словно девчата, выскочили на мысок юные березки»; «пахнуло...березовым соком с хвойным настоем»; «березняк вперемешку с кедрами и соснами»; «заросли рябинника, березняка, череможника»). Один раз в тексте береза упоминается в роли культового дерева угров - в эпизоде описания священной поляны: «На толстых, корявых от старости березах висят саженные разноцветные ткани» [2, с. 186]. П. Бахлыков, безусловно, соотносит березу с культом общеугорской богини Калтащ, которую связывают с рождением и смертью. Береза в качестве «дома Калтащ» является «семантическим центром мироздания» (А. Сагалаев), осуществляя функции Древа жизни, поскольку соотносится с воспроизводством человеческих жизней в «среднем мире», а богиня-матерь Калтащ, восседающая на семиствольной березе, олицетворяет собой источник существования [5, с. 86,88$]$. Сходные функции березы как одного из основных воплощений божества плодородия Н. Шутова отмечает в удмуртской культуре, указывая, что в качестве дара к стволу березы часто привязывались лоскутки и полотенца $[15$, c. 64]. Не противоречит культ березы и славянским представлениям. В народной традиции береза может выступать как символ женского начала, как «счастливое» дерево, связываемое с благополучием семьи, рождением ребенка, оберегающее от зла, и одновременно она может соотноситься с нечистой силой и душами умерших [14, с. 44-46].

В качестве священных объектов у народов Сибири чаще других деревьев почитаются кедр и лиственница. В этом качестве оба дерева в романе расположены на священной поляне напротив друг друга. Здесь автор более значимую роль отводит древней гордой лиственнице: именно на ее стволе вырублен шаманом идол «с глазами..., обрамленными кусочками бронзы», а между корневищ «лежат принесенные в дар всемогущим духам» старинные монеты [2, с. 185]. На кедре висели «приклады»жертвенные дары в виде шкур животных разных времен. Четвертое выделенное на древнем капище дерево - ель: она ближе всех к «шаманскому» дереву, на ней висят звериные и животные черепа («атрибуты» шаманского места). Но в описании угодий «современного шамана» Паньки функции всех культовых деревьев отведены кедру: на толстых стволах этих деревьев вырезаны лица духов, уже покрытые мхом либо вырубленные недавно («молодые еще проливают янтарную слезу» [2, с. 130]); на суках висят медвежьи черепа, оленьи и лосиные рога; здесь происходит обряд камлания. Такое выделение кедра соответствует традиционным представлениям угров: это дерево считается священным у многих этнических групп, с ним связаны культовые места и шаманские обряды (в том числе в районе Васюгана [5, с. 85], примыкающего к Юганскому заповеднику), он мог соотноситься с важными божествами - Мир-сусне-хумом [9, с. 373-374, 388] или даже с Нуми-Торумом [5, с. 86]. Для мифопоэтического сознания угров (и также славян) характерно сближение дерева и храма как священных мест, где совершались обряды. Соотнесение деревьев с невидимыми духами подчеркивает связь мифологемы с анимистическими представлениями: природа - мир, где царствуют духи, а не люди.

Выбор священного дерева чаще всего был обусловлен особенностями растительного мира данной местности. Выделение кедра, ели и сосны соответствует реальному природному ландшафту Западной Сибири (особенно Юганского края), распространенностью на территории этих пород деревьев. Характеризуя природу Югры, писатель постоянно подчеркивает высоту и мощь деревьев: «гигантские вековые ели», «огромный кедр», «могучие деревья», «высокие вершины лиственниц и елей», «мачтовые сосны и ели», «огромная, со сломанной вершиной ель», «крепкие смолистые еловые сучья». Акцент на древнем возрасте деревьев дополняет возникающие ассоциации: «вековые ели и кедры», «на вершине многовековой сосны», «высокая сухая сосна», «старая, в три обхвата, ель». Табуацию крупных деревьев Д. Зеленин относил к проявлениям ранних верований, характерных для 
примитивных народов, - тотемизму и фетишизму [6, с. 40, с. 67-68], что подчеркивает древность, архаичность мировоззрения, сохраненного не только угорскими этносами, но и переселившихся на эти земли русских. Стремление П. Бахлыкова выявить диалектику текущего и вечного приводило к тому, что реальные образы деревьев по ходу развития основной философской мысли становились овеществленными символами, вызывая ассоциации и аналогии, обосновывающие натурфилософское понимание отношений человека и природы.

Подводя итог проведенным наблюдениям, отметим следующее. В творчестве П. Бахлыкова особое значение имеет образ «места», играющего исключительную роль в искусстве, о чем писал еще Платон, отмечавший, что все сущее должно занимать какое-нибудь пространство, включающее и некие нематериальные конструкты, - то, что греческий философ определял понятием «эйдос» $[10$, c. 415,600,$]$. Для П. Бахлыкова таким местом являлась территория Югании. В картине мира, представленной автором, важнейшими моделирующими средствами реального и мифологического «места» - пространства выступает архетип дерева и его варианты, которые имеют различную символику и смысловую наполненность, трансформируясь в мифологемы Мирового древа и Древа жизни.

Овеществленным символом Мирового дерева, отражающего вертикальную структуру мироздания и являющегося маркером как сакрального центра, так и реального ландшафта, в романе выступают преимущественно кедр и отчасти ель. Функционирование мифологемы Дерева в романе связано также с березой, сосной и лиственницей, предстающих в качестве культовых объектов и одновременно указателей природных особенностей территории. Образ Дерева в романе несет дополнительную смысловую нагрузку, так как включает в себя содержательные стороны мифологемы Дерева жизни, воплощающего (в универсальной концепции мира) жизнь во всем ее многообразии и полноте проявлений. Модель Мирового Древа в большей степени соотносима с образом кедра, структурирующего текст на всех уровнях, являясь «центром» происходящих в романе событий.

Введение мифопоэтической символики и привлечение ее семантического потенциала (несмотря на некоторую осторожность в использовании мифологем) позволило П. Бахлыкову соотнести уникальную территорию Югры с системой «вечных», общечеловеческих ценностей. Одновременно использование семантики мифологемы Мирового древа дало возможность автору подчеркнуть основную идею своей концепции природы: природное бытие по отношению к другим формам земной жизни должно быть признано объективным и первичным, единство человека с природным миром определено изначальным (космическим) порядком.

\section{СПИСОК ИСТОЧНИКОВ И ЛИТЕРАТУРЫ}

1. Абдуллина Л.И. Творческая мастерская: индивидуальный почерк и территориальное самосознание// Геопоэтика писателей Сибири и Алтая: сборник научных статей. Барнаул: АлтГПУ, 2016. 168 с.

2. Бахлыков П.С. Медвежья падь: Роман. Тюмень: СофтДизайн, 1997. 240 с.

3. Бедарева И.А. Базовые пространственные мифологемы в русской литературе Горного Алтая ХХ века // Филологические науки. Вопросы теории и практики. 2016. № 10 (64). Ч. 3. С. 20-22.

4. Бурцева Ж.В. Крайний Север как геополитический образ в литературе малочисленных народов севера Якутии // Вестн. Удм. ун-та. Сер. История и филология. 2020. Т. 30, вып. 2. С. 337-342.

5. Волдина Т.В. Образ древа жизни в традиционной культуре обских угров в контексте реинкарнации // Финно-угорский мир. 2015. № 4. С. 84-90.

6. Зеленин Д.К. Тотемы-деревья в сказаниях и обрядах европейских народов. М.-Л.: Изд-во АН, 1937.80 с.

7. Косарев М.Ф. Образ дерева в мифоритуальной традиции сибирских народов // Миропонимание древних и традиционных обществ Евразии. Москва, 2006. С. 239-253.

8. Мифы народов мира: Энциклопедия. Электронное издание. М. 2008. 1147 с. URL: http://www.indostan.ru/ biblioteka/knigi/ 2730/3412_1_o.pdf

9. Петрухин В.Я. Мифы финно-угров. Москва: Астрель: АСТ: Транзиткнига, 2005. 463 с.

10. Платон. Парменид // Сочинения. Т. 2. М.: «Мысль», 1970. 611 с.

11. Подвижник из Угута: Бахлыков Петр Семенович: Неопубликованные и малоизвестные страницы творчества. Тюмень: Изд-во Ю. Мандрики, 2000. 144 с.

12. Полякова Л.В. Филологическая регионалистика как наука: к постановке проблемы // Филологическая регионалистика. 2012. № 2 (8). С. 7-12.

13. Распутин В.Г. Собрание сочинений в 2-х томах. Т. 2. Калининград: «Янтарный сказ», 2001. 640 с.

14. Славянская мифология. Энциклопедический словарь. Изд. 2-е. М.: Международные отношения, 2002.512 с. 
15. Шутова Н.И. Дерево в традиционном удмуртском мировоззрении // Ежегодник финно-угорских исследований. 2011 .№ 2. С. 56-71.

16. Gieysztor A. Mitologia Słowian. Warszawa: Wydawnictwa Uniwersytetu Warszawskiego, 2006. 407 s.

Поступила в редакцию 13.07.2020

Куликова Ирина Михайловна, кандидат филологических наук, доцент кафедры философии и права

БУ ВО «Сургутский государственный университет»,

628412, Россия, Тюменская область, г. Сургут, ул. Ленина, 1

E-mail:kim0153@mail.ru

ORCID: 0000-0001-5472-6024; SPIN-код: 2789 - 3060,

\section{I.M. Kulikova SEMANTIC FILLING OF THE TREE MYTHOLOGEME IN NATURPHILOSOPHY OF P.S. BAKHLYKOV}

DOI: $10.35634 / 2412-9534-2021-31-3-608-613$

The article deals with the semantic variants of the mythologeme "a tree" in the novel of the Ugra writer P. Bakhlykov "Bear's Pad". In the work, the mythologeme is one of the dominants of the formal and substantial organization of the artistic space. This mythologeme plays an important role in the natural philosophy of the author. It allows you to describe the basic parameters of life and reconstruct the universal mythopoetic concept of the world order. The semantic structure of the image of a tree in the novel goes back to the archetypal foundations of the worldview of the Russian and Khanty peoples inhabiting Siberia. The article analyzes the meaning and functions of real natural objects - cedar, birch, spruce, larch, pine, their role in mythology, in the formation of sacred space, in cult practice. These trees can serve as symbols of the World Tree and the Tree of Life. The main role in the novel is given to the image of a cedar, the cult of which was most developed in this territory.

Keywords: P.S. Bakhlykov, novel “Bear's Pad”, mythologeme, World Tree, Tree of Life, Ugric mythology, Slavic mythology.

\section{REFERENCES}

1. Abdullina L.I. Tvorcheskaya masterskaya: individual'nyj pocherk i territorial'noe samosoznanie [Creative workshop: individual handwriting and territorial identity] // Geopoetika pisatelej Sibiri i Altaya: sbornik nauchnyh statej [Geopoetics of the writers of Siberia and Altai: collection of scientific articles]. Barnaul: AltGPU, 2016. 168 p. (In Russian).

2. Bakhlykov P. Medvezh'ya pad': Roman [Bear Pad: Novel]. Tyumen': Soft Design, 1997. 240 p. (In Russian)

3. Bedareva I.A. Bazovye prostranstvennye mifologemy v russkoy literature Gornogo Altaya XX veka [Basic spatial mythologems in the Russian literature of Gorny Altai in the XX centure] // Filologicheskiye nauki. Voprosy teorii $\mathrm{i}$ praktiki [Philological sciences. Questions of theory and practice]. 2016. № 10 (64). Part 3. P. 20-22 (In Russian)

4. Burtseva Zh.V. Krayniy Sever kak geopoliticheskiy obraz v literature malochislennych narodov severa Yakutii [The extreme North as a geopoetical image in the literature of the indigenous peoples of the north of Yakutia] // Vestnik Udmurtskogo universiteta. Seriya Istoriya i filologiya [Vestik of Udmurt University. Series History and Philology]. 2020. Tom. 30. Vyp. 2. P. 337-342 (In Russian)

5. Voldina T.V. Obraz dreva zhizni $v$ traditsionnoj kul'ture obskikh ugrov v kontekste reinkarnatsii [The image of the tree of life in the traditional culture of the Ob Ugrians in the context of reincarnation]. Finno-ugorskij mir [FinnoUgric world]. 2015. № 4. P. 84-90. (In Russian)

6. Zelenin D.K. Totemy-derev'ya v skazaniyakh i obryadakh yevropeyskikh narodov [Totems-trees in the legends and rites of European peoples]. M.-L.: Izd-vo of the Academy of Sciences, 1937. 80 p. (In Russian)

7. Kosarev M.F. Obraz dereva v miforitual'noy traditsii sibirskikh narodov [The image of a tree in the mythological tradition of Siberian peoples] // Miroponimaniye drevnikh i traditsionnykh obshchestv Yevrazii [The outlook of ancient and traditional societies of Eurasia], Moscow. P. 239-253. (In Russian)

8. Mify narodov mira: Jenciklopedija. Jelektronnoe izdanie [Myths of the peoples of the world: Encyclopedia. Electronic Edition]. Ed. by S.A. Tokarev. 2008. 1147 p. URL: http://www.indostan.ru/biblioteka/knigi/2730/ 3412_1_o.pdf (In Russian)

9. Petrukhin V.Ya. Mify finno-ugrov [Myths of the Finno-Ugric peoples]. Moscow: Astrel': AST: Tranzitkniga, 2005. 463 p. (In Russian)

10. Platon. Parmenid [Plato. Parmenides]. Sochinenija [Works]. Moscow: «Thought», 1970. Vol. 2. 600 p. (In Russian) 
11. Podvizhnik iz Uguta: Bakhlykov Petr Semenovich: neopublikovannye I maloizvestnye stranitsy tvorchestva [The Ascetic from Ugut: Bakhlykov Peter Semenovich: Unpublished and little-known pages of creativity]. Tyumen': Publishing house Y. Mandrika, 2000. 144 p. (In Russian)

12. Polyakova L.V. Filologicheskaya regionalistika kak nauka: k postanovke problemy [Philological regional studies as science: to the problem statement] // Filologicheskaya regionalistika [Philological regional studies]. 2012. № 2 (8). P. 7-12. (In Russian)

13. Rasputin V.G. Sobraniye sochinenij v 2-kh tomakh. Tom 2. [Collected works in 2 volumes. Vol. 2]. Kaliningrad: «Yantarnyy skaz», 2001. 640 p. (In Russian)

14. Slavjanskaya mifologia: Entsiklopedicheskij slovar' [Slavic mythology: Encyclopedic dictionary]. Moscow: Ellis Lak, 1995. 416 p. (In Russian)

15. Shutova N.I. Derevo v traditsionnom udmurtskom mirovozzrenii [Tree in the traditional Udmurt views] // Yezhegodnik finno-ugorskikh issledovaniy. 2011. № 2. S. 56-71 [Yearbook of Finno-Ugric studies]. 2011. No. 2. P. 56-71 (In Russian)

16. Gieysztor A. Mitologia Słowian. Warszawa: Wydawnictwa Uniwersytetu Warszawskiego, 2006. 407 p. (In Polish)

Received 13.07.2020

Kulikova I.M., Candidate of Philology, Associate Professor, at Department of Philosophy and Law

Surgut State University

Lenina st., 1, Surgut, Tyumen region, Russia, 628412

E-mail:kim0153@mail.ru

ORCID: 0000-0001-5472-6024; SPIN-code: 2789 - 3060 